\title{
Polymyxin B-Conjugated $\alpha 2-$ Macroglobulin as an Adjunctive Therapy to Sepsis: Modes of Action and Impact on Lethality
}

\author{
Gerd Birkenmeier, Silke Nicklisch, Christiane Pockelt, Andualem Mossie, Volker Steger, \\ Christiane Gläser, Sunna Hauschildt, Elke Usbeck, Klaus Huse, Ulli Sack, Michael Bauer, \\ and Angelika Schäfer
}

Institute of Biochemistry (G.B., S.N., C.P., A.M., E.U., A.S.) and Department of Immunobiology, Institute of Zoology (S.H.), University of Leipzig, Leipzig, Germany; Emergency and Care Medicine, Leipzig, Germany (V.S.); Institute of Human Genetics and Medical Biology, University of Halle, Halle, Germany (C.G.); Leibniz Institute for Age Research-Fritz Lipmann Institute, Jena, Germany (K.H.); Institute of Clinical Immunology and Transfusion Medicine, Leipzig, Germany (U.S.); and Clinic for Anesthesiology and Intensive Care Therapy, Jena, Germany (M.B.)

Received March 10, 2006; accepted May 15, 2006

\begin{abstract}
A drug targeting both the inflammatory initiators (lipopolysaccharide; LPS) and mediators [tumor necrosis factor- $\alpha$ (TNF- $\alpha$ )] should have advantage over a "single-factor targeting strategy" in sepsis prevention trials. We have prepared conjugates of polymyxin $\mathrm{B}(\mathrm{PMB})$ and the cytokine binding protein $\alpha 2$-macroglobulin (A2M). The conjugate binds TNF- $\alpha$ as well as LPS as studied by electrophoresis and phase partitioning. Compared with free $\mathrm{PMB}$, the conjugate is nontoxic to cells and does not affect the viability of human monocytes. The A2M-PMB conjugate binds to the A2M receptor (CD91/low-density lipoprotein receptor-related protein 1) with affinity similar to that of the nonmodified protein. Fluorescein isothiocyanate-labeled LPS in the presence of $\mathrm{A} 2 \mathrm{M}-\mathrm{PMB}$ is rapidly transported into fibroblasts for degradation via receptor-mediated endocytosis. In vitro, A2M-PMB demonstrated inhibition of LPS-induced se-
\end{abstract}

cretion of TNF- $\alpha$ from isolated monocytes as well as in the whole blood assay. The efficacy of the drug was tested in mice after induction of acute inflammation (LPS model) and after induction of a polymicrobial sepsis by cecal ligation and puncture (CLP) model. Treatment of mice with A2M-PMB up to 250 $\mu \mathrm{g} / \mathrm{g}$ body weight was not toxic to the animal. When the drug was administered 30 min before or 30 min after the LPS challenge, a survival rate of 90 and $70 \%$, respectively, was obtained compared with the placebo control group (5\%). A2M-PMB also protected mice after induction of polymicrobial sepsis when administered $30 \mathrm{~min}$ before CLP. These results support our hypothesis that $\mathrm{A} 2 \mathrm{M}-\mathrm{PMB}$ acts as a polyvalent drug to target different host mediators as well as sepsis inducer at the same time.
In the past several years, mortality in patients with sepsis syndrome has decreased somewhat, but in those patients with septic shock and multiple organ failure, mortality still exceeds 50\% (Danai and Martin, 2005). This high mortality is observed despite ventilatory, hemodynamic, metabolic, and renal support. Some patients-in particular, patients with genetic polymorphisms associated with low or moderate TNF response-survive the ordeal more often, but it remains frus-

This research was supported by Saxon State Agency for Environment and Geology Grant AZ 56-8811.61/85). A.M. is supported by the Deutsche Akademische Austauschdienst.

Article, publication date, and citation information can be found at http://jpet.aspetjournals.org.

doi:10.1124/jpet.106.104265. trating not being able to stop the downhill course leading to multiple organ failure and death in other patients that results from overwhelming inflammation. New therapies have been sought and tested, including those preventing the biological activity of pathogen-associated molecular patterns, such as endotoxin or the downhill host response, most notably TNF- $\alpha$. Based on a wealth of animal studies, anti-inflammatory strategies, such as neutralizing TNF- $\alpha$, have been advocated to provide adjunctive therapy to the patient who continues to deteriorate in the face of considerable support in the intensive care unit. Unfortunately, these anticytokine therapies have not dramatically reduced mortality in doubleblind, placebo-controlled trials involving thousands of patients, although there is a consistent but statistically non-

ABBREVIATIONS: TNF, tumor necrosis factor; LPS, lipopolysaccharide; PMB, polymyxin B; A2M, $\alpha 2$-macroglobulin; IL, interleukin; FITC, fluorescein isothiocyanate; LAL, Limulus amebocyte lysate; WST-1, 4-[3-(4-iodophenyl)-2-(4-nitrophenyl)-2H-5-tetrazolio]-1,3-benzene disulfonate; PBS, phosphate-buffered saline; MA, methylamine; TBS, Tris-buffered saline; PBST-T, phosphate-buffered saline/Tween 20; PEG, polyethylene glycol; FCS, fetal calf serum; CLP, cecal ligation and puncture; HMGB1, high mobility group box 1. 
significant decrease in mortality associated with anti-inflammatory therapies for the individual phase II and III studies and some benefit in meta-analyses. It seems that systemic inflammation in sepsis requires more than anticytokine monotherapy to significantly reduce mortality in the acute phase of hyperinflammation or possibly also immune-reconstituting therapies in the later phase of overt immune paralysis based on the individual immune status of the patient. One intuitively promising avenue in the treatment of sepsis would be targeting the biological activity of LPS by either neutralization or enhancement of the rate of its clearance (Yethon and Whitfield, 2001; Lake et al., 2004). However, monoclonal antibodies against the active lipid A moiety of endotoxin have been developed and therapeutically applied in clinical trials without convincing success (Llewelyn and Cohon, 1999).

Another important compound capable of neutralizing lipid A is polymyxin B (PMB) (Neter, 1956). This cationic amphiphilic cyclic decapeptide antibiotic has been shown to neutralize the toxicity of lipid A in vitro and in animal models of endotoxemia (Lake et al., 2004). Because soluble PMB was found to be nephrotoxic and neurotoxic, attempts have been made to decrease the toxicity of PMB without compromising its anti-LPS effect. One approach to capitalize on the potential neutralizing properties of PMB is the conjugation of PMB to polymers such as dextran (Bucklin et al., 1995) or immunoglobulin G (Drabick et al., 1998).

Another potential agent that may broaden the therapeutic window of sepsis is the protease inhibitor $\alpha 2$-macroglobulin (A2M), a tetrameric glycoprotein $(720 \mathrm{kDa})$ present in human plasma $(2-4 \mathrm{mg} / \mathrm{ml}$ ), which is produced by hepatocytes, monocytes, and macrophages (Sottrup-Jensen, 1989). Upon reaction with proteases or reactive amines, A2M changes its conformation, which initiates high-affinity binding of several cytokines involved in the pathogenesis of sepsis, such as TNF- $\alpha$, IL-1 $\beta$, IL- 6 as well as transforming growth factor- $\beta$ (LaMarre et al., 1991; Birkenmeier, 2001; Gourine et al., 2002). Simultaneously, receptor recognition sites are excavated, which mediate binding of the so called "transformed" inhibitor to its cellular receptor, CD91 or low-density lipoprotein receptor-related protein 1 (Herz et al., 1988). Thus, A2M may act as a universal carrier to enhance uptake and degradation of substances into/within cells. It is proposed that the A2M-CD91 axis has a great potential to the regulation of cytokine homeostasis in blood and tissue (Gonias et al., 1994; Birkenmeier, 2001). Recently, Webb and Gonias (1998) demonstrated the preventive effect of chemically modified A2M in a mouse model of sepsis. They suggested that the mechanism of action of $\mathrm{A} 2 \mathrm{M}$ is due to binding and neutralization of inflammatory cytokines.

In the present study, which is the first in its type, we combined the A2M-based cytokine clearance activity with the LPS-neutralizing activity of PMB by the preparation of an A2M-PMB conjugate. The obtained conjugate demonstrates unique properties such as 1) binding and clearance of inflammatory cytokines, 2) receptor-mediated uptake and degradation of LPS, and 3) abolition of PMB toxicity. The results indicate that an A2M-PMB conjugate exceeds the activity of a dextran-PMB antidote currently used in clinical trials and offers a new approach to control inflammatory disorders.

\section{Materials and Methods}

Materials. All buffers and solutions were prepared of endotoxinfree water. Glass ware was sterilized at $200^{\circ} \mathrm{C}$ for $4 \mathrm{~h}$. Polymyxin B (5291; lot B42430) was purchased from Calbiochem (Schwalbach, Germany). 1-ethyl-3-(3-Dimethylaminopropyl)carbodiimide (E-7750; lot 25H0024), fluorescein-5-isothiocyanate-lipopolysaccharide (FITC-LPS) (F-3665; lot. 80k4136), LPS (Escherichia coli Serotype O111:B4), and methylamine (M-0505; lot. 091K2613) were purchased from Sigma (Taufkirchen, Germany).

CD91 (04-03), MacroNat (06-02), MacroTrans (06-01), and A2Mmethylamine (MA) (05-01) were obtained from BioMac GmbH (Leipzig, Germany). The Limulus amebocyte lysate assay (LAL) (CCL-1000; 50-647U) was obtained from BioWhittaker (Taufkirchen, Germany). Mouse anti-PMB-IgM (2047) was a gift from HyCult (Uden, The Netherlands); biotin-labeled goat anti-mouse-IgM (E0465; lot 129), and HRP-labeled streptavidin (P0397; lot. 059) were purchased from Dako (Hamburg, Germany). Cell proliferation reagent WST-1 (1644807) was obtained from Roche Diagnostics (Mannheim, Germany). D-Galactosamine-HCl (48250) was purchased from Fluka (Seelze, Germany).

${ }^{125} \mathrm{I}-\mathrm{TNF}-\alpha(43.5 \mathrm{mBq} / \mathrm{mmol})$ was obtained from GE Healthcare (Freiburg, Germany). All culture media used were purchased from Invitrogen (Karlsruhe, Germany).

Mouse anti-human TNF- $\alpha$ (551220), biotin-labeled mouse antihuman TNF- $\alpha$ (554511), recombinant TNF- $\alpha$ (554618), and the BD CBA mouse inflammatory kit (552364) were obtained from BD Biosciences PharMingen (Heidelberg, Germany).

Endotoxin Removal. LPS-free plastic and glass materials were used consistently. To ensure that there was no significant LPS contamination in the final protein preparation, the protein solutions were passed over EndTrap columns as described by the manufacturer (311063; EndoTrap 5/1; Profos AG, Regensburg, Germany).

Preparation of Human A2M. Fresh human citrated plasma was obtained from healthy volunteers. Plasma was dialyzed against LPSfree water overnight at $4^{\circ} \mathrm{C}$. Precipitations were removed by centrifugation $(10,000 \mathrm{~g})$, the clear supernatant was mixed with zinc-chelate (iminodiacetate)-Sepharose gel (plasma/gel ratio of 1:1) in binding buffer (50 mM sodium phosphate and $150 \mathrm{mM} \mathrm{NaCl}, \mathrm{pH}$ 6.5) for $2 \mathrm{~h}$ at $4^{\circ} \mathrm{C}$ under continuous shaking. The suspension was transferred to a column $(3.5 \times 20 \mathrm{~cm})$ and washed with 10 gel volumes of binding buffer. To remove weakly bound proteins, the column was washed with $90 \mathrm{mM}$ imidazole in binding buffer $(10 \times$ gel volumes), and elution was performed with $50 \mathrm{mM}$ sodium phosphate and $50 \mathrm{mM}$ EDTA, $\mathrm{pH}$ 8.0. The pooled fractions containing A2M were concentrated by ultrafiltration (cut-off of 30,000; Vivaspin concentrator; Vivascience, Hannover, Germany), to approximately $20 \mathrm{mg} / \mathrm{ml}$. Final purification was achieved by size-exclusion chromatography (HighLoad 16/60; Superdex 200) in PBS using the ÄKTA-Purifier (GE Healthcare). The obtained A2M was $98 \%$ pure with a degree of transformation of less than $3 \%$. The LPS content of the final A2M preparation as measured by the Limulus amebocyte lysate assay was $1.5 \pm 0.6 \mathrm{pg} / \mathrm{mg}$.

Coupling of PMB to A2M. Three different methods of coupling were tested.

Covalent binding of PMB to A2M. Twenty-five milligrams of A2M was dialyzed against $20 \mathrm{mM} \mathrm{NaCl}$ and dissolved in $25 \mathrm{ml}$ of dialyzing buffer. PMB (26 mg) was added, and the $\mathrm{pH}$ was adjusted to $\mathrm{pH} 5.5$ with $0.01 \mathrm{~N} \mathrm{HCl}$. Under mild stirring, $370 \mathrm{mg}$ of 1-ethyl-3-(3-dimethylaminopropyl)carbodiimide was added, and incubation was continued for $1 \mathrm{~h}$ at $22^{\circ} \mathrm{C}$. Then, additional $370 \mathrm{mg}$ of 1-ethyl-3-(3dimethylaminopropyl)carbodiimide was added and stirring continued for $1 \mathrm{~h}$. The $\mathrm{pH}$ was kept constant at $\mathrm{pH} 5.5$ by titration throughout the coupling. The solution was ultrafiltrated using a Vivaspin Concentrator (cut-off 100,000) and simultaneously washed with 100 $\mathrm{ml}$ of buffer ( $50 \mathrm{mM}$ sodium phosphate and $300 \mathrm{mM} \mathrm{NaCl}, \mathrm{pH} 6.0$ ) to remove free PMB. Final washing was with $100 \mathrm{mM}$ sodium phosphate, $\mathrm{pH} 8.0$, followed by concentrating the protein solution to $2 \mathrm{ml}$. 
The A2M-PMB complex was then treated with 0.2 M MA to induce transformation of A2M $\left(2 \mathrm{~h}\right.$ at $\left.22^{\circ} \mathrm{C}\right)$. After dialysis against PBS, the $\mathrm{PMB} / \mathrm{A} 2 \mathrm{M}$ ratio was determined immunologically. The degree of transformation was quantified using the MacroNat and MacroTrans test kits.

Noncovalent entrapment of PMB by A2M. This method is based on the finding that during transformation of A2M by methylamine, small, soluble peptides are entrapped by the cavities of the inhibitor. Thus, A2M (25 mg/ml) was mixed with $500 \mathrm{M}$ excess of PMB in $2 \mathrm{ml}$ of $0.1 \mathrm{M}$ sodium phosphate, $\mathrm{pH} 8.0$, and treated with $0.2 \mathrm{M}$ MA for $4 \mathrm{~h}$ at $22^{\circ} \mathrm{C}$. Free PMB and excess of MA were removed by extensive ultrafiltration as described above. The degree of transformation and the PMB/A2M ratio were determined immunologically by immunoassays and dot blots.

Adsorption by thermal treatment. According to Adlakha et al. (2001), small peptides can adsorb to A2M by long-time incubation at higher temperature. Thus, A2M ( $5 \mathrm{mg} / \mathrm{ml})$ and $500 \mathrm{M}$ excess of PMB were dissolved in $0.1 \mathrm{M}$ sodium phosphate, $\mathrm{pH}$ 8.0, and incubated for $16 \mathrm{~h}$ at $37^{\circ} \mathrm{C}$. After reaction, the free PMB was removed by ultrafiltration.

Binding of TNF- $\alpha$ to A2M and A2M-PMB. Binding studies were accomplished by incubation of $37 \mathrm{pmol}$ A2M-MA or A2M-PMB with $50,000 \mathrm{cpm}{ }^{125} \mathrm{I}-\mathrm{TNF}-\alpha$ in a total volume $20 \mu \mathrm{l}$ of PBS-T for $4 \mathrm{~h}$ at $37^{\circ} \mathrm{C}$. The samples were loaded onto the top of a polyacrylamide gradient gel (4-20\%) and run under nondenaturing conditions as described previously (Lauer et al., 2001). The gel was stained by Coomassie Brilliant Blue R-250, dried and exposed to Hyperfilm MP (GE Healthcare) for $6 \mathrm{~h}$ at $-80^{\circ} \mathrm{C}$ using an intensifying screen.

Preparation of Dextran-PMB Conjugates. Dextran T70-PMB conjugate was prepared using the periodate method according to Bocher et al. (1997). The bound PMB was determined by elementary analysis yielding a coupling of $180 \mu \mathrm{g}$ of $\mathrm{PMB} / 1 \mathrm{mg}$ of dextran (w/w).

Detection of Bound PMB by Western Blot. A2M-PMB conjugates were separated by SDS-polyacrylamide gel electrophoresis (Laemmli, 1970) and transferred to a blotting nitrocellulose membrane (Protran BA85, 104096; Whatman Schleicher \& Schuell, Dassel, Germany). After blocking (5\% defatted milk in TBS) for $2 \mathrm{~h}$, the membrane was incubated with mouse anti-PMB IgM (1:1000) in 5\% defatted milk in TBS-T for $2 \mathrm{~h}$. Following washing, biotin-labeled goat anti-mouse-IgM (1:5000) was added $(2 \mathrm{~h})$, and then the membrane was incubated with streptavidin-HRP (1:3000) in 5\% defatted milk, TBS-T, for $1 \mathrm{~h}$. Color development was achieved with diaminobenzidine and $\mathrm{H}_{2} \mathrm{O}_{2}$.

Quantification of PMB by Dot Blot. Different concentrations of A2M-PMB or a standard dextran-PMB (180 $\mu \mathrm{g}$ of PMB/mg of dextran) solution, respectively, were transferred onto a blotting membrane using a dot blot chamber (Bio-Rad, Hercules, Germany). The membrane was blocked by 5\% defatted milk in TBS and incubated with mouse anti-PMB-IgM $(1: 1000 ; 1 \mathrm{~h})$, with biotin-labeled goat anti-mouse-IgM (1:5000; $1 \mathrm{~h})$, and finally with HRP-labeled streptavidin $(1: 3000 ; 1 \mathrm{~h})$. After washing, the membrane was developed using the ECL Plus Western blotting detection system (RPN2132; GE Healthcare). The concentration of PMB bound to A2M was determined after scanning the dot densities and areas by comparison with standard samples of dextran-PMB.

Receptor Binding Analysis. Ninety-six-well titer plates (NUNC GmbH \& Co. KG, Wiesbaden, Germany) were coated with $2 \mu \mathrm{g} / \mathrm{ml}$ CD91 in $0.1 \mathrm{M} \mathrm{NaHCO}_{3}$ overnight. Plates were washed and incubated with $200 \mu \mathrm{l}$ of buffer (20 mM HEPES, $150 \mathrm{mM} \mathrm{NaCl}, 5 \mathrm{mM}$ $\mathrm{CaCl}_{2}, 1 \mathrm{mM} \mathrm{MgCl}_{2}$, and $0.05 \%$ Tween 20) containing increasing concentrations of A2M-MA and A2M-PMB conjugate for $3 \mathrm{~h}$ at $37^{\circ} \mathrm{C}$. The plates were washed and incubated in parallel settings either with polyclonal HRP-labeled rabbit anti-human A2M (1:2000) or with mouse anti-PMB-IgM (1:1000) in conjunction with biotin-labeled goat anti-mouse IgM (1:3000) and HRP-labeled streptavidin (1:3000). Substrate development was achieved with $o$-phenylene diamine and $\mathrm{H}_{2} \mathrm{O}_{2}$.
Two-Phase Partitioning. A simple and fast method to study ligand-protein interaction in solution is partitioning in aqueous twophase systems composed of polyethylene glycol (PEG) and dextran (Birkenmeier et al., 1989a). This method can usefully be applied when the interacting species due to different surface properties partition in favor of opposite phases of a two-phase system. To study binding of LPS to A2M-PMB, we applied two-phase partitioning in aqueous two-phase systems ( $1 \mathrm{~g}$ ) composed of 5\% (w/w) PEG 6000 and $7.5 \%(\mathrm{w} / \mathrm{w})$ dextran T70 containing $10 \mathrm{mM}$ sodium phosphate and $20 \mathrm{mM} \mathrm{NaCl}, \mathrm{pH} 7.2$ (Birkenmeier et al., 1989a). A constant amount of $20 \mu \mathrm{l}$ of a FITC-LPS stock solution $(0.1 \mathrm{mg} / \mathrm{ml})$ were preincubated with increasing concentrations of A2M-MA or A2M$\mathrm{PMB}$, respectively, in a total volume of $100 \mu \mathrm{l}$ for $1 \mathrm{~h}$ at $37^{\circ} \mathrm{C}$. A volume of $100 \mu \mathrm{l}$ of these samples was then added to $900 \mu \mathrm{l}$ of a premixed two-phase system, mixed again by 30 inversions, and centrifuged (13,000 rpm; $1 \mathrm{~min}$ ) for phase separation. Aliquots of $100 \mu \mathrm{l}$ were withdrawn from the top and bottom phases and analyzed for fluorescence intensity to record partition of FITC-LPS (PerkinElmer LS50B apparatus). The concentration of A2M in both phases was determined immunologically. The partition of a substance between the two phases is described by the partition coefficient, $K$, determined as the ratio of the concentrations of the substance in the top and the bottom phase.

Cytokine Analysis. Human TNF- $\alpha$ was analyzed by sandwichenzyme-linked immunosorbent assay in 96-well titer plates (Maxisorb 446469; NUNC GmbH \& Co. KG) using the mouse anti-human TNF- $\alpha$ as capture antibody, the biotin-labeled mouse anti-human TNF- $\alpha$ as detecting antibody, and recombinant TNF- $\alpha$ as standard according to manufacturer's instructions. Measurement of inflammatory cytokines in mouse blood was accomplished by flow cytometry using the cytokine bead array kit from BD Biosciences (San Jose, CA).

LAL Assay. A quantitative chromogenic version of the LAL assay was used to calculate the LPS content in different samples.

Immunocytochemical Staining of Fibroblasts. Fibroblasts were cultured in Dulbecco's modified Eagle's medium supplemented with $10 \%$ FCS as described previously (Birkenmeier et al., 1989b). A2M-PMB (2 mg) was incubated with $5 \mu \mathrm{g}$ of FITC-LPS for $30 \mathrm{~min}$ at $22^{\circ} \mathrm{C}$ in the dark. The sample was separated onto NAP 0.5 Sephadex column eluted with TBS containing $5 \mathrm{mM} \mathrm{CaCl}_{2}$ and $1 \mathrm{mM}$ $\mathrm{MgCl}_{2}$. The breakthrough faction was collected, and aliquots were placed on chamber slides grown with human fibroblasts to $40 \%$ confluence. The cells were incubated with the A2M-PMB-FITC-LPS complex at $37^{\circ} \mathrm{C}$ to allow endocytosis of the complex. After $20 \mathrm{~min}$, the cells were washed with medium and finally fixed with $2 \%$ paraformaldehyde. Nuclei were counterstained with 4,6-diamidino-2phenylindole. Fluorescence was measured using an Axiolab microscope (Carl Zeiss, Jena, Germany)

Monocyte Isolation and Culture. Human monocytes were isolated by elutriation as described previously (Gerth et al., 2005). Isolated monocytes (purity of 96\%) were cultivated in RPMI 1640 medium (Invitrogen, Carlsbad, CA) supplemented with 1\% antibiotics $(100 \mu \mathrm{g} / \mathrm{ml}$ streptomycin and $100 \mathrm{U} / \mathrm{ml}$ penicillin) $1 \%$ glutamine, and $10 \%$ heat-inactivated FCS (Invitrogen). The cells were cultured at $37^{\circ} \mathrm{C}$ with $5 \% \mathrm{CO}_{2}$. In total, $10^{5}$ cells in $200 \mu \mathrm{l}$ of culture medium was added to each well of a 96 -well cell culture plate (Bio-One $\mathrm{GmbH}$, Frickenhausen, Germany) and incubated overnight. Cells were treated with substances to be analyzed, and the incubation was continued for definite time. The plates were centrifuged, and the cell-free supernatant was stored at $-80^{\circ} \mathrm{C}$ until analysis.

For toxicity measurement, cultured monocytes were pretreated for $4 \mathrm{~h}$ with free or immobilized PMB followed by adding $20 \mu \mathrm{l}$ of WST-1 reagent. The absorbance was read after $2 \mathrm{~h}$ at 450/620 $\mathrm{nm}$.

Whole-Blood Assay. Whole-blood assay was established to simulate in vivo conditions (Wilson et al., 1991; De Groote et al., 1992). In preliminary experiments, optimum conditions with respect to the stimulatory concentration of LPS and incubation time were established. Stimulation by $10 \mathrm{ng} / \mathrm{ml}$ LPS and an incubation time of $6 \mathrm{~h}$ 
were used throughout all whole-blood assay experiments. In detail, a volume of $200 \mu \mathrm{l}$ of freshly drawn heparinized blood was diluted with culture medium up to a total volume of $1 \mathrm{ml}$ in 24 -well culture plates. LPS, test substances, and blood were mixed and coincubated for $6 \mathrm{~h}$ at $37^{\circ} \mathrm{C}$ with $5 \% \mathrm{CO}_{2}$. At the end of incubation, samples were centrifuged at $13,000 \mathrm{~g}$ for $15 \mathrm{~min}$, and the supernatant was stored at $-80^{\circ} \mathrm{C}$ for further cytokine analysis.

LPS Mouse Model. The animal model of acute inflammation involved administration of $30 \mu \mathrm{g} / \mathrm{kg}$ LPS along with the sensitizing agent D-galactosamine $(1 \mathrm{~g} / \mathrm{kg})$ to inbred female BALB/c mice $(6-8$ weeks old; $15-25 \mathrm{~g}$ ) given before or after administration of either A2M-PMB, dextran-PMB, or PMB, respectively. All injections were made intraperitoneally in a volume of $250 \mu \mathrm{l}$. In this model, mice died within 6 to $10 \mathrm{~h}$ after LPS challenge. Lethality was monitored for the subsequent $48 \mathrm{~h}$.

Cecal Ligature and Puncture Model. The cecal ligation and puncture model induces polymicrobial sepsis due to an abscess in the peritoneal cavity of mice. In brief, mice were anesthetized with ketamine (83 mg/kg i.p.; Pfizer, Karlsruhe, Germany), and abdominal midline incision was made under sterile conditions, and the cecum was exposed, ligated to approximately $40 \%$ of length with 4-0 suture (Ethicon Vicryl; Johnson \& Johnson, St-Stevers-Waluve, Belgium), and punctured using a 20 -gauge needle (Singleton and Wischmeyer, 2003). Bowl content was extruded through the puncture hole to ascertain polymicrobial infection. The abdomen was closed in two layers, i.e., peritoneum and skin, separately using 4-0 suture. Sham-operated control mice underwent the same surgical procedure, but the cecum was neither ligated nor punctured. Signs of sepsis were observed 6 to $8 \mathrm{~h}$ after operation. Test substances were injected intraperitoneally in a volume of $250 \mu \mathrm{l}$ either before or after CLP. Survival and mortality rates were recorded on 7-day follow-up. Care of mice followed institutional guidelines, and all animal experiments were approved by the local ethics committee.

Cytokine Analysis in Mouse Blood after LPS Challenge. Control mice (four in each group) were injected intraperitoneally with LPS/D-galactosamine as described above, and blood was obtained by heart puncture 2,4 , and $6 \mathrm{~h}$ after challenge. In comparison with controls, nine mice (three in each group) were treated with 250 $\mu \mathrm{g} / \mathrm{g}$ A2M-PMB $30 \mathrm{~min}$ before LPS administration. Ten minutes before blood sampling, mice were injected with heparin $(1 \mathrm{U} / \mathrm{g}$ body weight). Blood plasma was obtained and subjected to cytokine analysis by flow cytometry.

Statistics. Experimental results are expressed as mean \pm S.E.M. Statistical significance was determined using Student's $t$ test. Survival data are presented as a percentage, and Fisher's exact test was used to compare survival rate of the treated and control groups.

\section{Results}

\section{Preparation of A2M-PMB Conjugates}

A2M purified from plasma moves as slow-migrating protein in rate electrophoresis (Fig. 1A). For comparison, methylamine-transformed A2M displays increasing mobility and migrates as fast-moving band. The purified A2M was used to prepare PMB conjugates applicable in cell culture experiments and animal studies. The final conjugate was expected to exhibit high LPS binding capacity and strong affinity for TNF- $\alpha$ as well as for CD91.

Conjugates of PMB and A2M were prepared by three different methods. Covalent coupling of PMB to A2M by means of carbodiimide yielded a conjugate containing $4 \mathrm{~mol}$ of PMB/ mol of A2M, corresponding to approximately $7 \mu \mathrm{g}$ of $\mathrm{PMB} / \mathrm{mg}$ of A2M. Bound PMB resisted SDS treatment under reducing conditions and was immunologically colocalized with the 360$\mathrm{kDa}$ dimer, with higher A2M aggregates (nonreduced) and

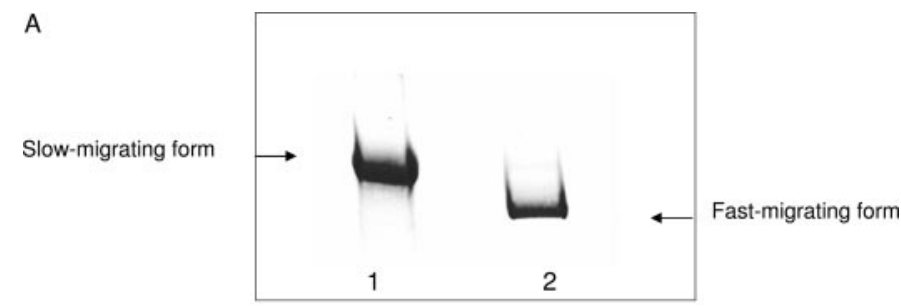

B

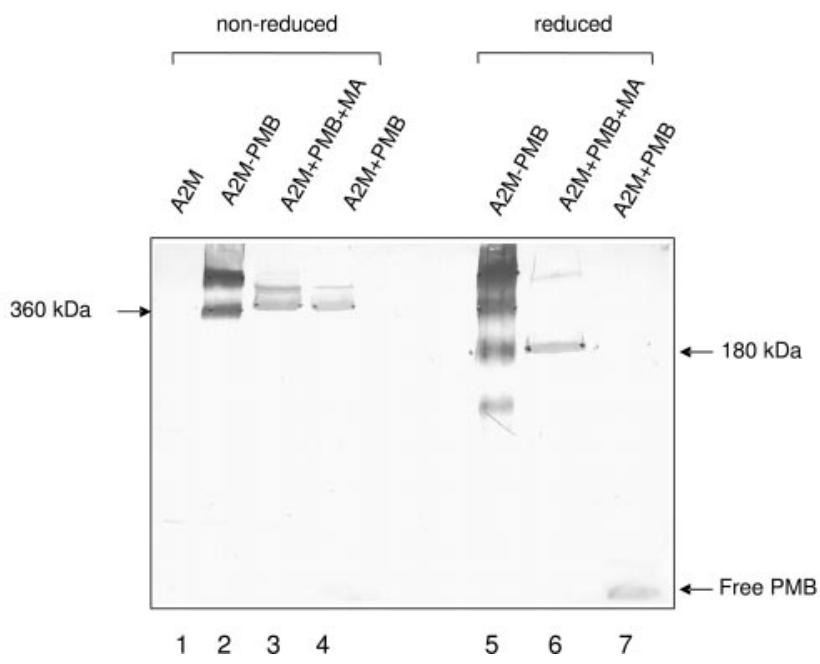

Fig. 1. A, separation of purified native A2M and methylamine-transformed A2M by rate electrophoresis. An amount of $10 \mu \mathrm{g}$ of purified A2M (lane 1, slow-migrating form) and methylamine-treated A2M-MA (lane 2, fast-migrating form), respectively, was separated by rate electrophoresis and stained by Coomassie Brilliant Blue R-250 as described previously (Birkenmeier et al., 2003). B, Western blot of different A2M-PMB conjugates separated by nonreduced and reduced SDS-polyacrylamide gel electrophoresis. Lane 1, $10 \mu \mathrm{g}$ of A2M; lanes 2 and 5, $10 \mu \mathrm{g}$ of A2M-PMB prepared according to coupling method A; lanes 3 and $6,10 \mu \mathrm{g}$ of A2MPMB prepared according coupling method B; and lanes 4 and 7, $10 \mu \mathrm{g}$ of A2M-PMB prepared according to coupling method C. Immunological detection of PMB was performed as described under Materials and Methods.

with A2M fragments (reduced), respectively (Fig. 1B). No free PMB was detected by Western blot.

To avoid possible masking of functional groups within the receptor binding domain at the $\mathrm{C}$ terminus of $\mathrm{A} 2 \mathrm{M}$ due to covalent modification, a second method of conjugation was applied based on the induction of a conformation change by interruption of the internal thiol esters of the inhibitor. This was accomplished by treating A2M with methylamine in the presence of excess of PMB. During the reaction the cavities of A2M become closed and small molecules such as PMB are trapped physically. Surprisingly, the trapped PMB was also resistant to SDS treatment and was found to be associated with the $360-\mathrm{kDa}$ nonreduced band and the $180-\mathrm{kDa}$ reduced band, respectively. The final product yielded a molar ratio (PMB/A2M) of only 0.8 .

Thermal activation was used to adsorb antigenic peptides to A2M as described recently (Adlakha et al., 2001). This coupling method gave insufficient results $(0.5 \mathrm{~mol}$ of PMB/ mol of A2M), and the complex did not resist SDS treatment under reducing conditions. PMB was stripped out of the complex and moved in the position of free PMB (Fig. 1B). It is to be expected that PMB could be liberated from the complex in vivo. Thus, we preferred to use the covalent attachment of PMB to A2M to yield stable and highly substituted complexes. 


\section{Analysis of Receptor Binding}

A precondition of our assumption was that the generated A2M-PMB complex has retained its high-affinity binding to the cellular receptor of A2M, CD91, to mediate clearance of coabsorbed LPS in addition to A2M-associated inflammatory cytokines. Therefore, we studied the binding of A2M-PMB to immobilized CD91 by enzyme-linked immunosorbent assay (Fig. 2). The conjugate was found to bind with comparable affinity for CD91 as unmodified A2M-MA ( $K_{\text {aff }}$ A2M-MA = $1.83 \pm 0.3 \mathrm{nM}$ versus $\left.K_{\text {aff }} \mathrm{A} 2 \mathrm{M}-\mathrm{PMB}=0.5 \pm 0.2 \mathrm{nM}\right)$. When we analyzed the binding of the A2M-PMB conjugate by antibodies directed against the PMB moiety, the affinity was only slightly different from the previous affinity $\left(K_{\text {aff }}\right.$ A2M$\mathrm{PMB}=3.62 \pm 0.7 \mathrm{nM}$ ), indicating the absence of nonspecific binding of the positively charged PMB to CD91. As expected, dextran-PMB did not bind to CD91, corroborating the specificity of A2M-receptor interaction.

\section{Analysis of LPS Binding to A2M-PMB Conjugates}

To follow-up on the interaction between A2M-PMB and LPS, an aqueous two-phase system composed of 5\% PEG $6000 / 7.5 \%$ dextran T70 was used. A2M-PMB partitioned in favor of the lower dextran-rich phase with a partition coefficient of $K=0.59$, and FITC-LPS partitioned in favor of the PEG-rich upper phase $(K=2.05)$. In case of an interaction between the substances, the $K$ value of FITC-LPS was changed as the concentration of A2M-PMB in the system increased (Fig. 3A). Because, the partition of particles is governed mainly by the property and area of their surface exposed to the medium, it was expected that A2M-PMB affects the partition of FITC-LPS and not vice versa. As shown in Fig. 3A, the $K$ value of FITC-LPS approaches the value for A2M-PMB. As expected, A2M-MA did not significantly affect the partition of FITC-LPS. Unspecific binding of the FITC

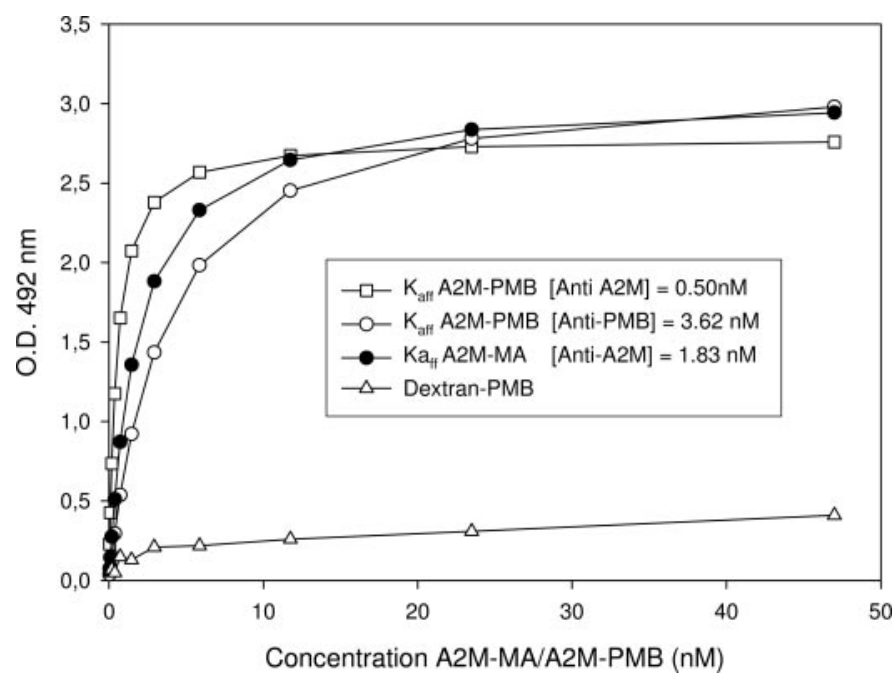

Fig. 2. Binding of A2M-PMB conjugate to immobilized CD91. Titer plates (96-well) were coated with $2 \mu \mathrm{g} / \mathrm{ml}$ CD91 overnight. After washing with PBS-T, increasing concentrations of A2M-PMB were incubated with the receptor in $10 \mathrm{mM}$ HEPES, $150 \mathrm{mM} \mathrm{NaCl}, 5 \mathrm{mM} \mathrm{CaCl}, 2.5 \mathrm{mM} \mathrm{MgCl}_{2}$, and $0.05 \%$ Triton $\mathrm{X}-100$ (incubation buffer) at $37^{\circ} \mathrm{C}$ for $3 \mathrm{~h}$. After repeated washing with incubation buffer, bound A2M was detected with rabbit HRP-labeled-anti-A2M (1:2000) $(\bullet, \square)$, and PMB was detected with mouse anti-PMB-IgM (1:1000) in conjunction with biotin-labeled goat anti-mouse IgM (1:3000) followed by incubation with HRP-labeled streptavidin $(1: 3000)(\bigcirc, \diamond)$. For comparison, the binding of A2M-MA is shown (•).

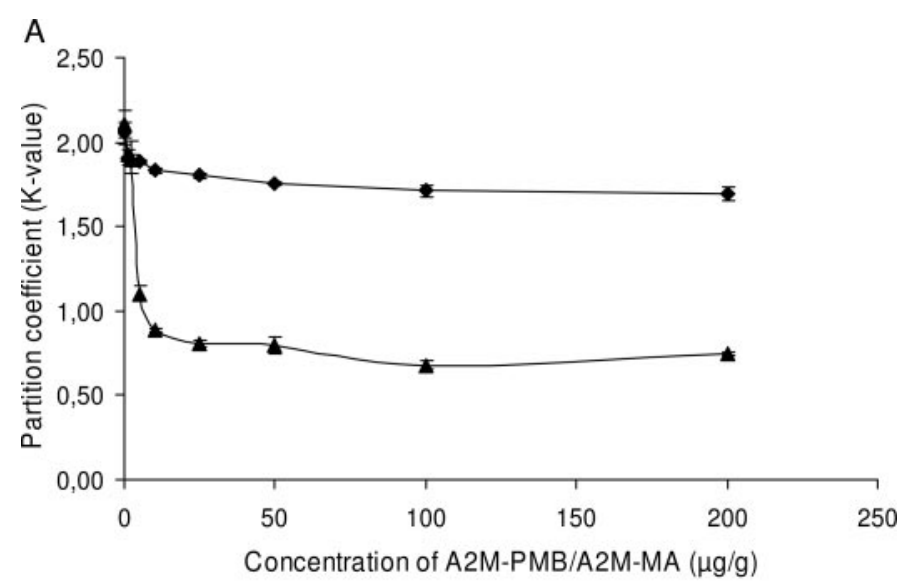

B

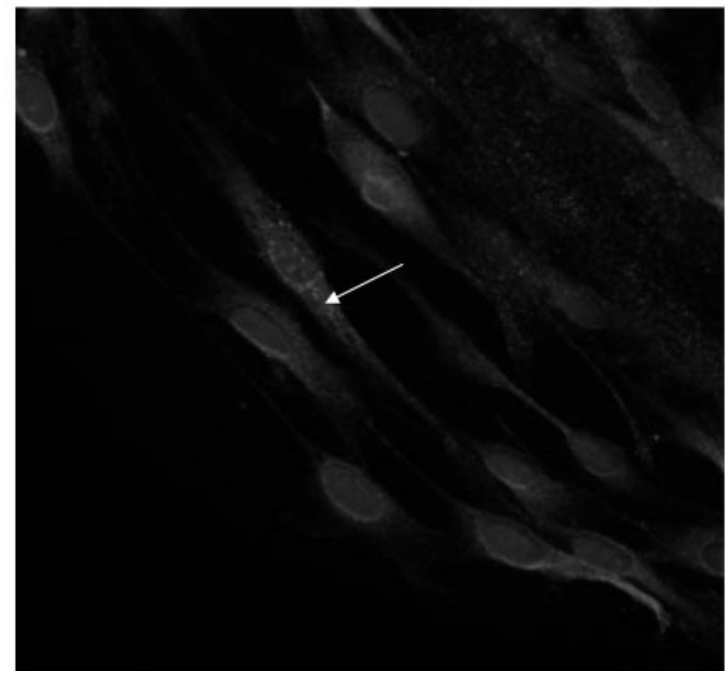

Fig. 3. A, two-phase systems (1 g) used were composed of 5\% (w/w) PEG 6000 and $7.5 \%(\mathrm{w} / \mathrm{w})$ dextran T70 containing $10 \mathrm{mM}$ sodium phosphate and $20 \mathrm{mM} \mathrm{NaCl}, \mathrm{pH} 7.2$. A constant amount of FITC-LPS was partitioned in the presence of increasing concentrations of A2M-MA or A2M$\mathrm{PMB}$, respectively, at $22^{\circ} \mathrm{C}$. After mixing and centrifugation, aliquots of $100 \mu \mathrm{l}$ were removed from the top and bottom phases and analyzed for fluorescence (at $490 \mathrm{~nm}_{\text {excitation }} / 520 \mathrm{~nm}_{\text {emission }}$ ) and for protein (immunoassay). $\mathbf{\Delta}$, partition of FITC-LPS in presence of A2M-PMB, and $\bullet$, partition of FITC-LPS in the presence of A2M-MA. B, immunocytochemical staining of intracellular FITC-LPS in culture fibroblasts. Fibroblasts were incubated with A2M-PMB-FITC-LPS complexes at $37^{\circ} \mathrm{C}$ to allow CD91-mediated endocytosis of the complex. After $20 \mathrm{~min}$, the cells were washed with medium and finally fixed with $2 \%$ paraformaldehyde. Nuclei were counterstained with 4,6-diamidino-2-phenylindole. The arrow shows stained granules in the cytoplasm.

moiety to the inhibitor could be eliminated by control experiments using FITC alone in conjunction with A2M-MA.

\section{Receptor-Mediated Endocytosis of FITC-LPS Bound to A2M-PMB}

To show that FITC-LPS enters cells in conjunction with A2M-PMB, fibroblasts were incubated with preformed complexes of FITC-LPS and A2M-PMB. Fibroblasts were chosen because of their high expression level of CD91. The faint intracellular staining comprises cytoplasmic vesicles or granules, indicating that FITC-LPS was internalized via CD91 (Fig. 3B). The uptake could be blocked by addition of $500 \mathrm{nM}$ receptor-associated protein known to compete binding of all ligands to CD91 (Williams et al., 1992), indicating specificity of receptor binding (data not shown). 


\section{A2M-PMB Retained Binding of TNF- $\alpha$}

We have recently shown that $\mathrm{TNF}-\alpha$ binds preferably to transformed A2M rather than to the native inhibitor (Birkenmeier et al., 2003). Whether the covalent modification of A2M by PMB interferes with TNF- $\alpha$ binding was a question of interest. Figure 4 shows that A2M-MA and A2M-PMB bound radiolabeled TNF- $\alpha$ with comparable affinity. This indicates that covalent attachment of PMB did not affect binding of TNF- $\alpha$ to A2M.

\section{Functional Characterization of the PMB Conjugates in Cell Cultures}

A2M-PMB Is Not Toxic to Cells. It is known that free nonconjugated PMB is toxic to cells (Danner et al., 1989). We therefore tested the effect of PMB, PMB-conjugates, and free carriers on vitality of human monocytes by measuring the mitochondrial dehydrogenase activity in the WST-1 assay. PMB showed no toxicity at low concentrations $(<10 \mu \mathrm{g} / \mathrm{ml})$, but cell toxicity considerably increased at higher PMB concentrations (Fig. 5). As anticipated, immobilization of PMB to A2M abolished toxicity. Similar effects were seen when dextran-PMB was used. For control, the carriers alone did not affect cell viability (data not shown).

A2M-PMB Diminishes LPS-Induced TNF- $\alpha$ Release in Monocyte Cultures. To test the effect of PMB conjugates on LPS-induced TNF- $\alpha$ release in monocytes cultures, different control experiments had to be conducted. First, we studied whether the different conjugates and carrier may evoke TNF- $\alpha$ release in nonstimulated cells. Neither the conjugates nor free carriers were found to induce significant TNF- $\alpha$ release from monocytes (Fig. 6). This finding indicated that the conjugates were not contaminated by LPS during the different steps of preparation.

In a second set of controls, we tested whether A2M may affect TNF- $\alpha$ measurement in the immunoassay by inducing sequestration of the cytokine, restricting the accessibility of antibodies to TNF- $\alpha$. This would result in nonreliable determinations of TNF- $\alpha$ levels. We therefore, incubated TNF- $\alpha$ standards without and with $50 \mathrm{nM}$ and $500 \mathrm{nM}$ A2M-MA, respectively. The results indicate that even at high concentrations of A2M-MA, the outcome of the TNF- $\alpha$ assay was not altered (Fig. 7).

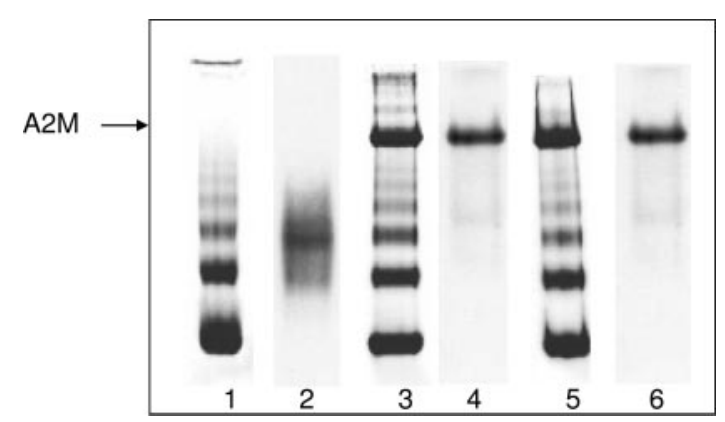

Fig. 4. Binding of ${ }^{125} \mathrm{I}-\mathrm{TNF}-\alpha$ to A2M-MA and A2M-PMB. An amount of 37 pmol of A2M-MA or A2M-PMB, respectively, was incubated with $50,000 \mathrm{cpm}{ }^{125} \mathrm{I}-\mathrm{TNF}-\alpha$ in a total volume of $20 \mu \mathrm{l}$ of PBS-T for $4 \mathrm{~h}$ at $37^{\circ} \mathrm{C}$ The samples were loaded onto the top of a polyacrylamide gradient gel $(4-20 \%)$ and run under nondenaturing conditions. The gel was stained by Coomassie Brilliant Blue R-250 (lanes 1, 3, and 5), dried, and exposed to Hyperfilm MP for $6 \mathrm{~h}$ at $-80^{\circ} \mathrm{C}$ (lanes 2, 4, and 6). Lanes 1 and 2, ${ }^{125} \mathrm{I}-\mathrm{TNF}-\alpha$; lanes 3 and $4,{ }^{125} \mathrm{I}-\mathrm{TNF}-\alpha+\mathrm{A} 2 \mathrm{M}-\mathrm{MA}$; and lanes 5 and 6 , ${ }^{125} \mathrm{I}-\mathrm{TNF}-\alpha+\mathrm{A} 2 \mathrm{M}-\mathrm{PMB}$. Albumin added to ${ }^{125} \mathrm{I}-\mathrm{TNF}-\alpha$ for stabilization occurs in different polymeric forms.

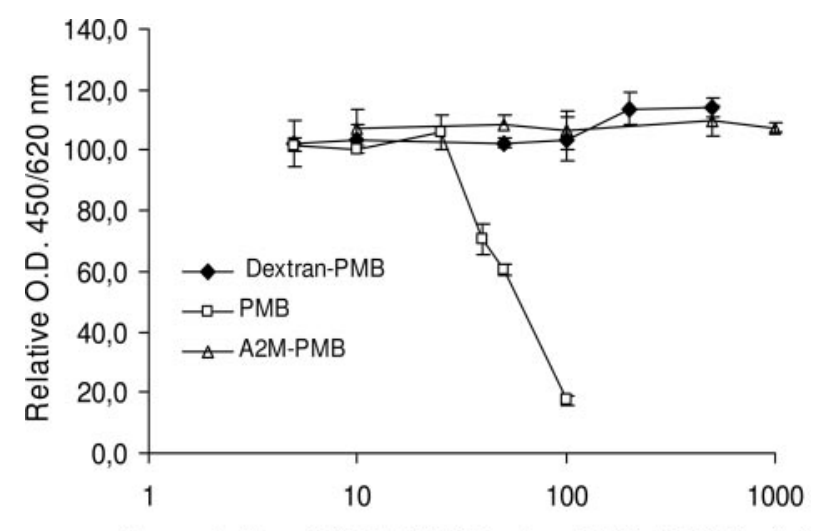

Concentration of A2M-PMB, Dextran-PMB, PMB $(\mu \mathrm{g} / \mathrm{ml})$

Fig. 5. Cytotoxicity of free PMB and PMB conjugates. For toxicity measurement, monocytes $\left(10^{5}\right.$ cells) were cultured in 96 -well culture plates in RPMI 1640 medium containing $10 \%$ FCS in the presence of free or immobilized PMB for $4 \mathrm{~h}$ at $37^{\circ} \mathrm{C}$ with $5 \% \mathrm{CO}_{2}$. After addition of $20 \mu \mathrm{l}$ of WST-1 reagent, the absorbance was read after $2 \mathrm{~h}$ at 450/620 nm.

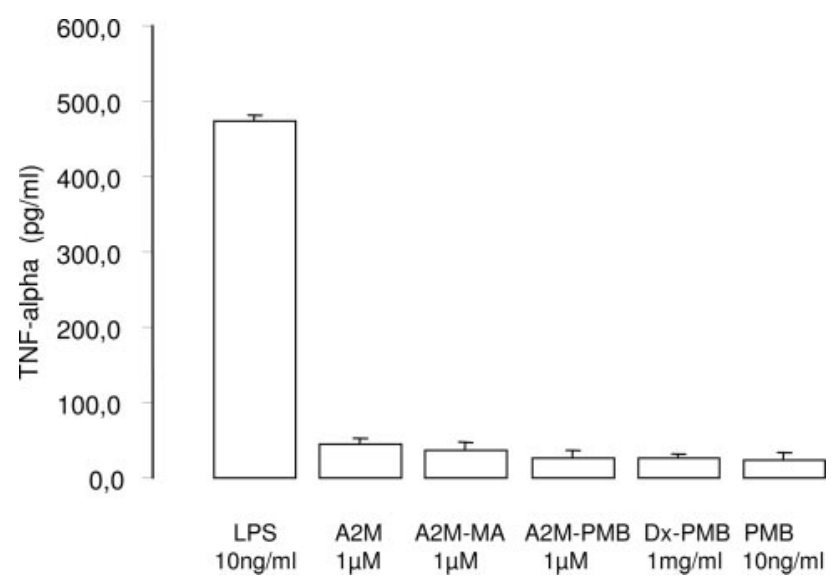

Fig. 6. Control of stimulatory activity of free PMB, PMB conjugates, and free carrier on TNF- $\alpha$ release from cultured human monocytes. Monocytes $\left(10^{5}\right.$ cells) were cultured 96-well culture plates in RPMI 1640 medium containing $10 \%$ fetal calf serum for $4 \mathrm{~h}$ at $37^{\circ} \mathrm{C}$ in the presence of different additives. TNF- $\alpha$ was measured in the supernatant by immunoassay. For comparison, monocytes were stimulated with $10 \mathrm{ng} / \mathrm{ml}$ LPS.

After completion these necessary control experiments, we studied the effect of PMB and PMB conjugates on LPSinduced TNF- $\alpha$ release from monocytes. The results shown in Fig. 8 depict the relative efficacy of PMB, A2M-PMB, and dextran-PMB normalized to the absolute concentrations of PMB in the sample.

After stimulation of cells with $10 \mathrm{ng} / \mathrm{ml}$ LPS, A2M-PMB significantly reduced the TNF- $\alpha$ level by approximately $90 \%$ at $1 \mu \mathrm{M}$ A2M-PMB, which approximately corresponds to a PMB content of $7 \mu \mathrm{g} / \mathrm{ml}$. This indicates that the prepared conjugate is an effective means to block monocyte activation under in vitro conditions of cell cultures.

The effectiveness of our conjugate was compared with a dextran-PMB conjugate used in previous sepsis treatment trials (Lake at al., 2004). As seen, that conjugate was less effective compared with A2M-PMB. Convincingly, no inhibition was observed at a dextran-PMB concentration that corresponds to a PMB content of $7 \mu \mathrm{g} / \mathrm{ml}$. This clearly shows that A2M-PMB exceeds inhibitory capacity of dextran-PMB by approximately 2 orders of magnitudes and is as effective as free PMB but without toxic side effects. 


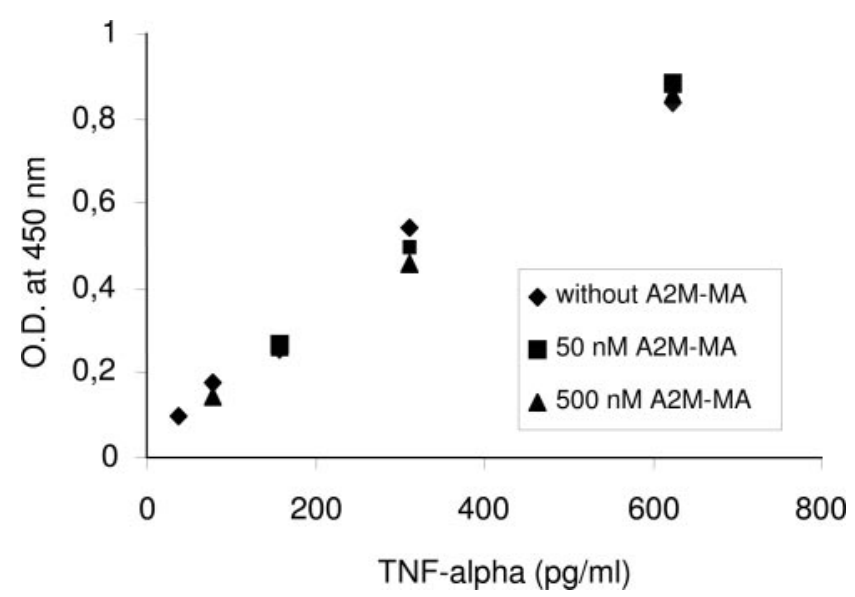

Fig. 7. Effect of A2M-MA on TNF- $\alpha$ measurement by immunoassay. Standard dilutions of recombinant TNF- $\alpha$ (15-2000 pg/ml) were mixed with buffer (PBS-T and 1\% bovine serum albumin) containing $50 \mathrm{nM}$ A2M-MA or $500 \mathrm{nM}$ A2M-MA, respectively, incubated for $3 \mathrm{~h}$ at $22^{\circ} \mathrm{C}$, and processed for analysis according to the protocol of the manufacturer.

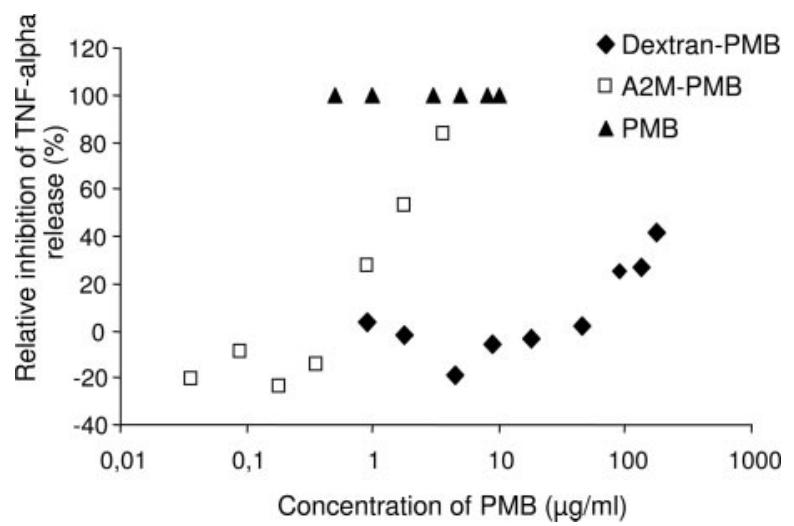

Fig. 8. Effect of A2M-PMB, dextran-PMB, and PMB on LPS-stimulated secretion of TNF- $\alpha$ in cultured monocytes. Human monocytes were cultured in RPMI 1640 medium containing $10 \%$ FCS. Cells were stimulated with LPS $(10 \mathrm{ng} / \mathrm{ml} ; 4 \mathrm{~h})$ at $37^{\circ} \mathrm{C}$ in the absence or presence of increasing concentrations of different additives. The cell supernatant was harvested and analyzed for TNF- $\alpha$. The figure shows comparative inhibitory effects of PMB, A2M-PMB, and dextran-PMB based on calculation of the total PMB content.

A2M-PMB Decreases LPS-Induced TNF- $\alpha$ Release in Whole Human Blood. Similar to monocyte cell culture experiments, nonconjugated carrier and PMB-carrier conjugates were tested in whole blood assays. No significant basal stimulation of TNF- $\alpha$ secretion was observed when the substances were tested at different concentrations in absence of LPS (data not shown). After stimulation with $10 \mathrm{ng} / \mathrm{ml}$ LPS, A2M-PMB effectively blocks TNF- $\alpha$ secretion by more than 95\% at $1 \mu \mathrm{M}$ (Fig. 9A). Nonconjugated A2M also inhibited cytokine release but with lower efficacy compared with the PMB conjugate. The effect of dextran-PMB conjugate on TNF- $\alpha$ release was also tested for comparative purposes and was found to be less inhibitory (Fig. 9B). Surprisingly, nonconjugated dextran is almost as potent as dextran-PMB, indicating that additional effects of the carrier should be taken into consideration. Because dextran obviously does not bind cytokines and is not rapidly cleared by receptor-mediated endocytosis, this observation illuminates an unknown effect of the polysaccharide.

A2M-PMB Protects Mice from LPS-Induced Lethality. First, we determined the toxicity of free PMB and A2M-
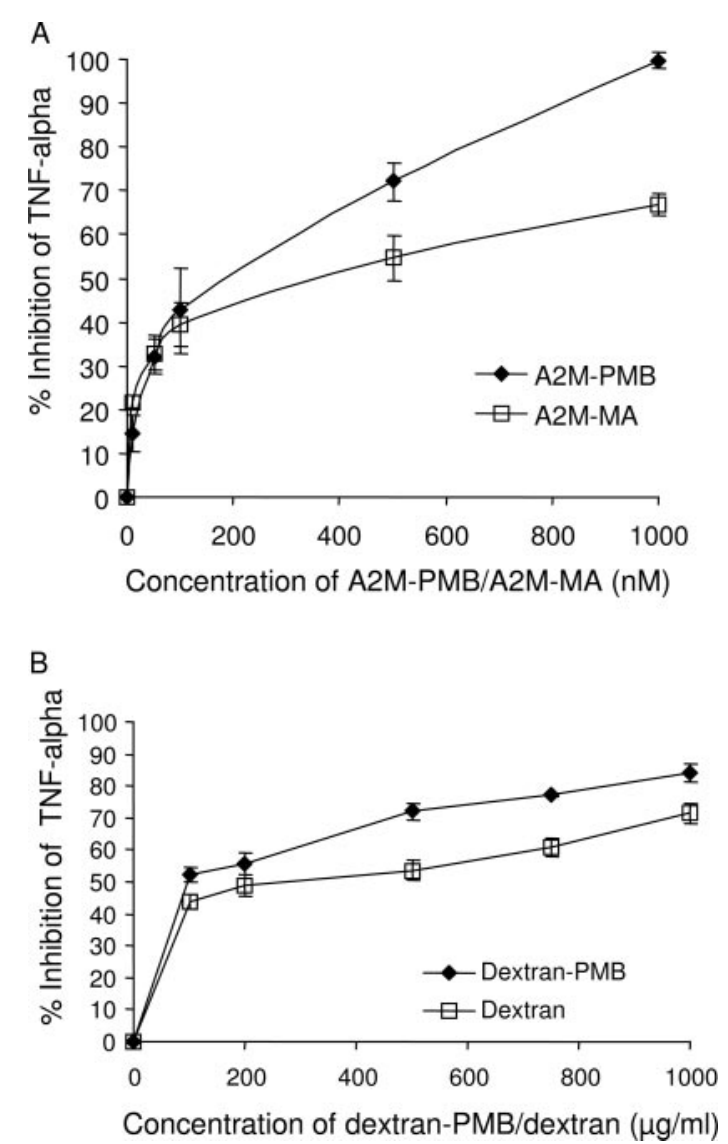

Fig. 9. Inhibition of TNF- $\alpha$ release by PMB conjugates studied by whole blood assays. Two hundred microliters of freshly drawn heparinized blood was diluted with culture medium up to a total volume of $1 \mathrm{ml}$ in 24-well culture plates. LPS $(10 \mathrm{ng} / \mathrm{ml})$ and increasing concentrations of substances to be tested were added, and the incubation was continued for $6 \mathrm{~h}$ at $37^{\circ} \mathrm{C}$ with $5 \% \mathrm{CO}_{2}$. The samples were removed, centrifuged at $13,000 \mathrm{~g}$ for $15 \mathrm{~min}$, and the supernatant was analyzed for TNF- $\alpha$ or stored at $-80^{\circ} \mathrm{C}$. A, inhibiting effect of A2M-PMB compared with the free carrier (mean \pm S.D. of three measurements). B, inhibiting effect of dextranPMB compared with the free carrier (mean \pm S.D. of three measurements).

PMB in mice. Intraperitoneal administration to mice of PMB $(0.5,1,2.5,5$, and $10 \mu \mathrm{g} / \mathrm{g}$ body weight) (five mice in each group) and A2M-PMB (25, 50, and $250 \mu \mathrm{g} / \mathrm{g}$ body weight) (three mice in each group), respectively, caused no deaths, indicating that PMB eventually released from the carrier in the body did not induce toxicity in animals. To induce sepsis, mice received by intraperitoneal injection LPS ( $30 \mu \mathrm{g} / \mathrm{kg}$ body weight) in conjunction with D-galactosamine $(1 \mathrm{~g} / \mathrm{kg}$ body weight). The lethality of this dose of LPS was found to be 95\% within $15 \mathrm{~h}$ after challenge. The protective effect of A2MPMB against LPS-induced lethality is shown in Table 1. Dose-dependent administration of A2M-PMB $(50-250 \mu \mathrm{g} / \mathrm{g}$ body weight) provided almost complete protection. Indiscernible less protection was observed when the conjugate was given after LPS challenge. The effect of dextran-PMB was less compared with A2M-PMB, which reflects the results of cell culture experiments shown in Figs. 8 and 9.

Time-dependent analysis of cytokines in the blood of LPSchallenged untreated and treated mice revealed reduction in blood levels of TNF- $\alpha$, IL-6, and monocyte chemoattractant protein-1 by treatment with A2M-PMB (Table 2). Small but nonsignificant effects were seen with IL-10, and no changes were found with interferon- $\gamma$ and IL-12p70. 
TABLE 1

Efficacy of A2M-PMB in protection of mice against LPS lethality

\begin{tabular}{lcr}
\hline Dose/Time of Administration & No. Dead Mice/Total & Survival \\
\hline & & $\%$ \\
A2M-PMB: $25 \mu \mathrm{g} / \mathrm{g} ; 30$ min before LPS & $6 / 10$ & 40 \\
A2M-PMB: $50 \mu \mathrm{g} / \mathrm{g} ; 30$ min before LPS & $0 / 10^{*}$ & 100 \\
A2M-PMB: $250 \mu \mathrm{g} / \mathrm{g} ; 30$ min before LPS & $5 / 10^{*}$ & 90 \\
A2M-PMB: $25 \mu \mathrm{g} / \mathrm{g} ; 30$ min after LPS & $4 / 10$ & 50 \\
A2M-PMB: $50 \mu \mathrm{g} / \mathrm{g} ; 30$ min after LPS & $3 / 10$ & 60 \\
A2M-PMB: $250 \mu \mathrm{g} / \mathrm{g} ; 30$ min after LPS & $20 / 21$ & 50 \\
Control $^{a}$ & $7 / 12$ & 42 \\
Dextran-PMB $^{b}: 26 \mu \mathrm{g} / \mathrm{g}$; 30 min before LPS & & 5 \\
\hline
\end{tabular}

* A2M-PMB versus control $(P<0.05)$

${ }^{a}$ Control mice were given $250 \mu \mathrm{l}$ of PBS intraperitoneally $30 \mathrm{~min}$ before LPS.

${ }^{b}$ This amount is equivalent to $250 \mu \mathrm{g} / \mathrm{g}$ A2M-PMB on basis of the PMB content.

TABLE 2

Effect of A2M-PMB on LPS-induced cytokine release in mice blood

\begin{tabular}{cccc}
\hline Cytokine & $\begin{array}{c}\text { Time of Blood } \\
\text { Sampling after } \\
\text { LPS Challenge }\end{array}$ & Control Mice & $\begin{array}{c}\text { Mice Treated } \\
\text { with A2M-PMB }\end{array}$ \\
\hline & $h$ & & \\
TNF- $\alpha(\mathrm{pg} / \mathrm{ml})$ & 2 & $949 \pm 188$ & $672 \pm 218$ \\
& 4 & $201 \pm 56$ & $77 \pm 40^{*}$ \\
$\mathrm{IL}-6(\mathrm{pg} / \mathrm{ml})$ & 6 & $144 \pm 45$ & $50 \pm 19^{*}$ \\
& 2 & $3829 \pm 804$ & $4215 \pm 824$ \\
& 4 & $1521 \pm 340$ & $1282 \pm 377$ \\
$\mathrm{MCP}-1(\mathrm{pg} / \mathrm{ml})$ & 6 & $554 \pm 195$ & $79 \pm 27^{*}$ \\
& 2 & $4650 \pm 560$ & $4055 \pm 1002$ \\
$\mathrm{IL}-10(\mathrm{pg} / \mathrm{ml})$ & 4 & $4685 \pm 952$ & $2037 \pm 386^{*}$ \\
& 6 & $4742 \pm 1136$ & $1856 \pm 663^{*}$ \\
& 4 & $61 \pm 14$ & $45 \pm 19$ \\
& 6 & $43 \pm 20$ & $15 \pm 9$ \\
& 4 & $66 \pm 26$ & $35 \pm 19$ \\
\hline
\end{tabular}

* A2M-PMB versus control mice at same time of blood sampling $(P<0.05)$.

A2M-PMB Protects Mice from Polymicrobial Infection. Three different cohorts of animals were studied. Sixteen mice were CLP-operated from which eight received the drug and eight PBS 30 min before operation. Another eight mice were sham-operated without administration of any solution. Properly sham-operated mice should have been treated as CLP mice; however, results from the foregoing paragraph showed neither toxicity of A2M-PMB nor any effect on lethality of mice. Therefore, we decided to omit treatment of sham-operated mice.

A2M-PMB (250 $\mu \mathrm{g} / \mathrm{g}$ body weight) as well as PBS were given in a total volume of $250 \mu \mathrm{l}$ as intraperitoneal bolus injection. In addition, a further eight mice were administered $50 \mu \mathrm{g} / \mathrm{g}$ dextran-PMB $30 \mathrm{~min}$ before operation. Usually, first symptoms of disease developed $8 \mathrm{~h}$ after surgery, and death occurred in control mice within 24 to $60 \mathrm{~h}$. As shown in Table $3,100 \%$ survival has been achieved in case of sham-operated

TABLE 3

Efficacy of A2M-PMB in protection of mice against polymicrobial infection

\begin{tabular}{lcc}
\hline Dose/Time of Administration & $\begin{array}{c}\text { No. Dead } \\
\text { Mice/Total }\end{array}$ & Survival \\
\hline & & $\%$ \\
Sham-operated mice & $0 / 8$ & 100 \\
A2M-PMB: $250 \mu \mathrm{g} / \mathrm{g} ; 30 \mathrm{~min}$ & $3 / 8$ & 63 \\
before CLP & $8 / 8$ & 0 \\
PBS $^{a} ; 30$ min before CLP & $6 / 8$ & 25 \\
Dextran-PMB & \\
before CLP $26 \mu \mathrm{g} / \mathrm{g} ; 30 \mathrm{~min}$ & &
\end{tabular}

${ }^{a}$ Control mice were given $250 \mu$ l of PBS intraperitoneally $30 \mathrm{~min}$ before CLP.

${ }^{b}$ This amount is equivalent to $250 \mu \mathrm{g} / \mathrm{g}$ A2M-PMB on basis of the PMB content. mice compared with controls injected with normal PBS. Administration of A2M-PMB 30 min before CLP resulted in a remarkable survival rate (63\% versus $0 \%$ in controls). In contrast, administration of equivalent amounts of dextranPMB showed less protection. Thus, the A2M-PMB conjugate turned out to be effective even in case of polymicrobial infection mimicking clinical sepsis.

\section{Discussion}

During the onset of sepsis, the inflammatory system becomes hyperactivated, involving both humoral and cellular defense mechanisms. Different cells, including endothelial and epithelial cells as well as neutrophils and macrophages, produce powerful proinflammatory mediators. The early release of cytokines such as TNF- $\alpha$ and IL- $1 \beta$ from target cells is stimulated by bacterial LPS. Therefore, it is understandable that most therapeutic strategies have targeted TNF- $\alpha$ and LPS (for review, see Riedemann et al., 2003). Unfortunately, most of these strategies did not improve survival of patients when studied in large clinical trials (Deans et al., 2005).

One reason might be that the therapeutic tools applied are directed to only a single pathogenetic factor, such as blocking of TNF- $\alpha$ by soluble TNF- $\alpha$ receptors (Reinhart and Karzai, 2001) or monoclonal antibodies (Tracey et al., 1987), neutralization of LPS by anti-endotoxin antibodies (Warren et al., 1993) or polymyxin B (Danner et al., 1989) as well as antagonizing IL-1 $\beta$ (McNamara et al., 1993) or migration inhibitory factor (Bernhagen et al., 1994). Second, exact timing of the therapeutic intervention seems to be crucial, because levels of TNF- $\alpha$ and IL- $1 \beta$ after an initial burst decline as the process proceeds. Sustainment of signs of sepsis at later stage is probably due to the release from the nucleus of HMGB1 (Yang et al., 2005). This is a highly conserved protein capable of binding primarily to cruciform DNA. LPSactivated monocytes release HMGB1 at late stages of disease between 8 and $32 \mathrm{~h}$. HMGB1 itself can stimulate monocytes to produce inflammatory cytokines. Third, TNF- $\alpha$ is an essential component of normal inflammatory responses, and prolonged neutralization of its activity may have potent immunosuppressive effects. Although the approach taken in many clinical trials has been to block completely the action of mediators, it is suggested to be more appropriate to modulate rather than to ablate the host response.

The proteinase inhibitor A2M is suggested to regulate cytokine homeostasis in blood and tissue (Birkenmeier, 2001). By bridging protease and cytokine metabolism, A2M is sug- 
gested to down-regulate excessive levels of cytokines, leaving physiological cytokine levels untouched. Furthermore, triggered by proteases liberated during inflammatory reaction, A2M may act as a regulatory switch between inflammatory and anti-inflammatory processes (Wu et al., 1998). Both inflammatory cytokines such as TNF- $\alpha$, IL- $1 \beta$, and IL- 6 as well as anti-inflammatory cytokines, such as transforming growth factor- $\beta 1$, are bound to A2M with high affinity. In most cases, binding occurs to transformed A2M as a result of a preceding interaction with a protease or reaction with small nucleophilic substances such as methylamine. Furthermore, oxidative stress molecules and radicals can modify the cytokine binding properties of the inhibitor (Wu et al., 1998). The state of conformation then decides whether inflammatory or antiinflammatory cytokines are released or bound and eliminated by receptor-mediated endocytosis via CD91. Clearance of CD91 ligands is fast with a half-time of $7 \mathrm{~min}$. Thus, the A2M and CD91 form an excellent clearance couple to flatten temporally elevated growth factor and cytokine spikes. This mechanism may provide an advantage that can be exploited for the treatment of inflammatory disorders.

Here, we reported for the first time the application of a conjugate composed of transformed A2M and PMB for treatment of sepsis. Previous studies showed that transformed A2M is capable of binding TNF- $\alpha$ (Wollenberg et al., 1991). On the other hand, the endotoxin-neutralizing activity of PMB is well known. But it was unknown whether a conjugate of both entities could be used in vivo to improve survival in sepsis. Because binding to the cellular receptor is essential for the efficacy of our drug, care had to be taken not to destroy the receptor-binding domains of the inhibitor located at the $\mathrm{C}$ terminus of each subunit. We therefore, studied different methods of coupling and analyzed the conjugate afterward with respect to interaction with LPS, TNF- $\alpha$, and CD91. The conjugate was found stable in terms of release of free PMB. This is an important question, because free PMB is assumed to be toxic to cells. After coupling, we treated the conjugate with methylamine to induce transformation, which is a precondition for cytokine and receptor binding. When we changed the protocol and conjugated PMB to methylaminetreated A2M, the receptor binding of the conjugate was impaired. This goes back to the fact that the receptor binding domains are hidden in the native A2M and are obviously not modified by PMB coupling. The conjugate was capable of recognizing LPS studied by phase partitioning in aqueous two-phase systems. This is an excellent method for studying interacting species in an almost complete aqueous solution avoiding unspecific adsorption to solid phases. Thus, we could clearly show that LPS binds to the PMB moiety and not to the carrier. Further tests revealed that covalent coupling of PMB did not significantly alter the affinity of A2M to its receptor. That ensures speedy removal of PMB-bound LPS from the circulation by receptor-mediated endocytosis. This is an important feature of the novel conjugate, which distinguishes the drug from other PMB derivatives. In those studies, PMB was chemically conjugated to dextran-70 used as plasma expander in the treatment of sepsis (Bucklin et al., 1995). Others have prepared PMB-soluble starch or PMBimmunoglobulin conjugates (Drabick et al., 1998). The well characterized PMB-dextran conjugate (PMX622) has been tested in different animal models of sepsis and in phase I trials in humans with success. However, clear efficacy was not demonstrated in a phase II trial of septic patients (Lake et al., 2004). Common to all these PMB-conjugates is their capability of neutralizing LPS. But what is the fate of adsorbed LPS? Obviously, dextran does not penetrate into tissue, and the half-life is long, between 5 and $20 \mathrm{~h}$ (Bucklin et al., 1995; Lukyanov et al., 2004). Likewise, immunoglobulin given intravenously for replacement therapy has a half-life of 20 to 35 days (Berger and Pinciaro, 2004). Thus, these conjugates accumulate LPS within the circulation, and it cannot be ruled out that it slowly releases from the complex and may stimulate cells. Furthermore, there are no studies abnegating the possibility that LPS immobilized to carrier-bound PMB is capable of stimulating cellular responses. Thus, a carrier that permanently removes LPS from circulation should be the better choice to counteract the LPS challenge. We could show that LPS is endocytosed via CD91 entering the lysosomal pathway for degradation. It is of interest to note that microinjected LPS did not induce nuclear factor- $\kappa \mathrm{B}$ translocation, indicating that intracellular LPS fails to induce an inflammatory response (Gerth et al., 2005). Therefore, internalization of LPS is an attractive way to abolish LPS toxicity in vivo.

A further point of consideration is that CD91 mediates transcytosis of its ligands through endothelial cell barriers (Burgess and Stanley, 1997). This could be of interest with respect to targeting also that part of LPS and TNF- $\alpha$ that entered the tissue. In contrast, dextran-PMB or immunoglobulin-PMB conjugates are not expected to penetrate into tissue.

LPS as well as TNF- $\alpha$ are considered as important factors that induce endothelial permeability, leading to circulatory collapse (Nooteboom et al., 2002). Compared with TNF- $\alpha$ and IL-1 $\beta$, no other cytokine has been shown to reproduce the dramatic hypotension and pathophysiological changes associated with septic shock. Thus, multifactorial inhibition of inflammatory initiators and mediators should have advantage over "a single-factor targeting strategy" in sepsis prevention trials. A recently published study has demonstrated that intraperitoneal injection of modified human A2M improves survival of mice after LPS challenge (Webb and Gonias, 1998). It was convincingly shown that the beneficial effect of A2M is due to binding and elimination of cytokines.

Our results clearly showed that the A2M-PMB conjugate was superior to dextran-PMB in inhibiting TNF- $\alpha$ release. When the inhibitory effect was calculated on total amount of PMB in the conjugates, the efficacy of A2M-PMB was approximately 2 orders of magnitude higher than that of dextranPMB. This dramatic improvement most probably results from the supportive clearance effect via CD91 of neutralized LPS, which presumably is a potential therapeutic advantage.

In addition to monocyte cultures, we tested A2M-PMB also in the whole blood assay. This was to create conditions close to in vivo that means in the presence of LPS binding proteins and other cellular components of the blood that communicate to each other after LPS challenge. These results were precisely corroborated by measurement of inflammatory cytokines in the blood of mice stimulated and treated with LPS and A2M-PMB, respectively. An inhibitory effect of A2MPMB on secretion of mouse TNF- $\alpha$, IL-6, and monocyte chemoattractant protein-1 was demonstrated. The results manifest the high efficacy of our conjugate in human and mouse blood, even in the presence of endogenous A2M. In the light 
of these findings, it is important to note that A2M-PMB was able to abrogate the deleterious effects of CLP-induced systemic polymicrobial infection and the resulting deleterious host response. The latter model is now considered "goldstandard" to develop adjunct therapies for sepsis (Esmon, 2004).

Together, these results support our hypothesis that A2MPMB acts as a polyvalent drug to target different host mediators as well as sepsis inducer at the same time. It offers new hope for sepsis treatment exploiting the physiological role of a human plasma protein.

\section{Acknowledgments}

We are grateful to H. Knaack for excellent assistance in cytokine analysis by flow cytometry.

\section{References}

Adlakha CL, Hart JP, and Pizzo SV (2001) Kinetics of nonproteolytic incorporation of a protein ligand into thermally activated $\alpha 2$-macroglobulin: evidence for a novel nascent state. $J$ Biol Chem 276:41547-41552.

Berger M and Pinciaro PJ; Flebogamma 5\% Investigators (2004) Safety, efficacy, and pharmacokinetics of Flebogamma $5 \%$ [immune globulin intravenous (human)] for replacement therapy in primary immunodeficiency diseases. J Clin Immunol 24:389-396.

Bernhagen J, Calandra T, and Bucala R (1994) The emerging role of MIF in septic shock and infection. Biotherapy 8:123-127.

Birkenmeier G (2001) Targetting the protease inhibitor and immune modulatory function of human $\alpha 2$ macroglobulin. Mod Aspects Immunobiol 2:32-36.

Birkenmeier G, Carlsson-Bostedt L, Shanbhag V, Kriegel T, Kopperschlager G, Sottrup-Jensen L, and Stigbrand T (1989a) Differences in hydrophobic properties for human alpha 2-macroglobulin and pregnancy zone protein as studied by affinity phase partitioning. Eur J Biochem 183:239-243.

Birkenmeier G, Heidrich K, Glaser C, Handschug K, Fabricius EM, Frank R, and Reissig D (1989b) Different expression of the alpha2-macroglobulin receptor/lowdensity lipoprotein receptor-related protein in human keratinocytes and fibroblasts. Arch Dermatol Res 290:561-568.

Birkenmeier G, Muller R, Huse K, Forberg J, Glaser C, Hedrich H, Nicklisch S, and Reichenbach A (2003) Human alpha2-macroglobulin: genotype-phenotype relation. Exp Neurol 184:153-161.

Bocher M, Boldicke T, Kiess M, and Bilitewski U (1997) Synthesis of mono- and bifunctional peptide-dextran conjugates for the immobilization of peptide antigens on ELISA plates: properties and application. J Immunol Methods 208:191-202.

Bucklin S, Lake P, Lögdberg L, and Morrison DC (1995) Therapeutic efficacy of a polymyxin B-dextran 70 conjugate in experimental model of endotoxemia. Antimicrob Agents Chemother 39:1462-1466.

Burgess JW and Stanley KK (1997) Estrogen-stimulated transcytosis of desialylated ligands and alpha2-macroglobulin in rat liver. Biochim Biophys Acta 1359:48-58.

Danai P and Martin GS (2005) Epidemiology of sepsis: recent advances. Curr Infect Dis Rep 7:329-334.

Danner RL, Joiner KA, Rubin M, Patterson WH, Johnson N, Ayers KM, and Parrillo JE (1989) Purification, toxicity and antiendotoxin activity of polymyxin B nonapeptide. Antimicrob Agents Chemother 33:1428-1434.

Deans KJ, Haley M, Natanson C, Eichacker PQ, and Minneci PC (2005) Novel therapies for sepsis: a review. J Trauma 58:867-874.

De Groote D, Zangerle PF, Gevaert Y, Fassotte MF, Beguin Y, Noizat-Pirenne F, Pirenne J, Gathy R, Lopez M, and Dehart I (1992) Direct stimulation of cytokines (IL-1 beta, TNF-alpha, IL-6, IL-2, IFN-gamma and GM-CSF) in whole blood. I. Comparison with isolated PBMC stimulation. Cytokine 4:239-248.

Drabick J Bhattacharjee AK, Hoover DL, Siber GE, Morales VE, Young LD, Brown SL, and Cross AS (1998) Covalent polymyxin-B conjugate with human immunoglobulin-G as an antiendotoxin reagent. Antimicrob Agents Chemother 42:583588.

Esmon CT (2004) Why do animal models (sometimes) fail to mimic human sepsis? Crit Care Med 32:219-222.

Gerth A, Grosche J, Nieber K, and Hauschildt S (2005) Intracellular LPS inhibits the activity of potassium channels and fails to activate NFkappaB in human macrophages. J Cell Physiol 202:442-452.

Gonias SL, LaMarre J, Crookston KP, Webb DJ, Wolf BB, Lopes MB, Moses HL, and
Hayes MA (1994) alpha 2-Macroglobulin and the alpha 2-macroglobulin receptor/ LRP. A growth regulatory axis. Ann NY Acad Sci 737:273-290.

Gourine AV, Tesfaigzi Y, Caluwaerts N, Leuven FN, and Kluger MJ (2002) The role of $\alpha 2$ macroglobulin on fever and cytokine response induced by LPS in mice. Am J Physiol 283:218-226.

Herz J, Hamann U, Rogne S, Myklebost O, Gausepohl H, and Stanley KK (1988) Surface location and high affinity for calcium of a 500-kd liver membrane protein closely related to LDL receptor suggest a physiological role as a lipoprotein receptor. EMBO (Eur Mol Biol Organ) J 7:4119-4127.

Laemmli UK (1970) Cleavage of structural proteins during assembly of the head of bacteriophage T4. Nature (Lond) 227:680.

Lake P, DeLeo J, Cerasoli F, Logdberg L, Weetall M, and Handley D (2004) Pharmacodynamic evaluation of the neutralization of endotoxin by PMX622 in mice. Antimicrob Agents Chemother 48:2987-2992.

LaMarre J, Wollenberg GK, Gonias SL, and Hayes MA (1991) Cytokine binding and clearance properties of protease activated $\alpha 2$ macroglobulin. Lab Investig 65:3-14.

Lauer D, Reichenbach A, and Birkenmeier G (2001) alpha 2-Macroglobulin-mediated degradation of amyloid beta 1-42: a mechanism to enhance amyloid beta catabolism. Exp Neurol 167:385-392.

Llewelyn M and Cohon J (1999) Anti-endotoxin antibodies in sepsis: a critical evaluation. Sepsis 3:39-45.

Lukyanov AN, Sawant RM, Hartner WC, and Torchilin VP (2004) PEGylated dextran as long-circulating pharmaceutical carrier. J Biomater Sci Polym Ed 15:621630.

McNamara MJ, Norton JA, Nauta RJ, and Alexander HR (1993) Interleukin-1 receptor antibody (IL-1rab) protection and treatment against lethal endotoxemia in mice. $J$ Surg Res 54:316-321.

Neter E (1956) Bacterial hemagglutination and hemolysis. Bacteriol Rev 20:166188

Nooteboom A, Van der Linden CJ, and Hendriks T (2002) Tumor necrosis factoralpha and interleukin-1beta mediate endothelial permeability induced by lipopolysaccharide-stimulated whole blood. Crit Care Med 30:2063-2068.

Reinhart K and Karzai W (2001) Anti-tumor necrosis factor therapy in sepsis: update on clinical trials and lessons learned. Crit Care Med 29:121-125.

Riedemann NC, Guo RF, and Ward PA (2003) Novel strategies for the treatment of sepsis. Nat Med 9:517-524.

Singleton KD and Wischmeyer PE (2003) Distance of cecum ligated influences mortality, tumor necrosis factor-alpha and interleukin-6 expression following cecal ligation and puncture in the rat. Eur Surg Res 35:486-491.

Sottrup-Jensen L (1989) $\alpha$-Macroglobulins: structure, shape, and mechanism of proteinase complex formation. J Biol Chem 264:11539-11542.

Tracey KJ, Fong Y, Hesse DG, Manogue KR, Lee AT, Kuo GC, Lowry SF, and Cerami A (1987) Anti-cachectin/TNF monoclonal antibodies prevent septic shock during lethal bacteraemia. Nature (Lond) 330:662-664

Warren HS, Amato SF, Fitting C, Black KM, Loiselle PM, Pasternack MS, and Cavaillon JM (1993) Assessment of ability of murine and human anti-lipid A monoclonal antibodies to bind and neutralize lipopolysaccharide. J Exp Med 177: 89-97.

Webb DJ and Gonias SL (1998) A modified human alpha 2-macroglobulin derivative that binds tumor necrosis factor-alpha and interleukin-1 beta with high affinity in vitro and reverses lipopolysaccharide toxicity in vivo in mice. Lab Investig 78:939 948 .

948.
Williams SE, Ashcom JD, Argraves WS, and Strickland DK (1992) A novel mechanism for controlling the activity of $\alpha 2$-macroglobulin receptor/low density lipoprotein receptor-related protein. Multiple regulatory sites for $39-\mathrm{kDa}$ receptorassociated protein. J Biol Chem 267:9035-9040.

Wilson BM, Severn A, Rapson NT, Chana J, and Hopkins P (1991) A convenient human whole blood culture system for studying the regulation of tumour necrosis factor release by bacterial lipopolysaccharide. J Immunol Methods 139:233-240

Wollenberg GK, LaMarre J, Rosendal S, Gonias SL, and Hayes MA (1991) Binding of tumor necrosis factor alpha to activated forms of human plasma alpha 2-macroglobulin. Am J Pathol 138:265-272.

Wu SM, Patel DD, and Pizzo SV (1998) Oxidized alpha2-macroglobulin (alpha2M) differentially regulates receptor binding by cytokines/growth factors: implications for tissue injury and repair mechanisms in inflammation. J Immunol 161:4356 4365 .

Yang H, Wang H, Czura CJ, and Tracey KJ (2005) The cytokine activity of HMGB1. J Leukoc Biol 78:1-8.

Yethon JA and Whitfield C (2001) Lipopolysaccharide as a target for the development of novel therapies in Gram-negative bacteria. Curr Drug Targets Infect Disord 1:91-106.

Address correspondence to: Prof. Gerd Birkenmeier, Institute of Biochemistry, Johannissalle 30, 04103 Leipzig, Germany. E-mail: birg@medizin.unileipzig.de 